\title{
Insightful Understanding of the Role of the Mechanical Properties in Defining the Reliability of All-Ceramic Dental Restorations: A Review
}

\author{
Mohammad Albakry \\ Department of Restorative Dental Sciences, Faculty of Dentistry, University of Najran, Najran, KSA \\ Email: albakrym@hotmail.com
}

How to cite this paper: Albakry, M. (2021) Insightful Understanding of the Role of the Mechanical Properties in Defining the Reliability of All-Ceramic Dental Restorations: A Review. Journal of Biomaterials and Nanobiotechnology, 12, 57-78.

https://doi.org/10.4236/jbnb.2021.124006

Received: September 13, 2021

Accepted: October 10, 2021

Published: October 13, 2021

Copyright $\odot 2021$ by author(s) and Scientific Research Publishing Inc. This work is licensed under the Creative Commons Attribution International License (CC BY 4.0).

http://creativecommons.org/licenses/by/4.0/

\begin{abstract}
Since the last two decades, restorative dentistry has been witnessing an increased acceptance of the use of the well-known all-ceramic materials for the fabrication of single dental restorations, such as inlays, onlays, crowns, anterior and posterior fixed partial dentures (PFPDs). These restorations certainly offer the potential for better biocompatibility coupled with superior aesthetic qualities, especially when compared with the conventional prostheses made from porcelain that is fused with metal ceramic restorations. However, brittleness and extreme sensitivity of all-ceramic materials to micro-like defects or cracks that are inherently present, or may grow, in their microstructure during different laboratory fabrication steps, during necessary clinical adjustments, or from post-placement chewing activity, remain major shortcomings of these dental restorations. In fact, many researchers are of the opinion that the improved mechanical properties can significantly improve the lifetime of all-ceramic restorations and result in enhanced reliability. Therefore, efforts of researchers, as well as manufacturers, have been directed towards the improvement of the mechanical properties in order to overcome such limitations. This article reviews the characterization of the most important mechanical properties that can delineate the behavior of all-ceramic dental materials upon loading. These include fracture mechanics, the brittle nature of ceramics, the relationship between microstructural features and fracture behavior, sources of cracks and flaws that may initiate a fracture and the effect of different fabrication procedures and/or clinical adjustments on the mechanical behavior of dental ceramics are also reviewed and discussed.
\end{abstract}

\section{Keywords}

Mechanical Properties, Fracture Mechanics, All-Ceramic Dental Restorations, 
Microstructural Features, Microcracks

\section{Introduction}

Tooth loss is a major oral health problem that has plagued humankind for centuries. It has inevitable and adverse effects on physical, mental and emotional health. In fact, tooth loss occurs for a variety of reasons: 1) dental caries; 2) trauma; and 3) gum diseases. Since time immemorial, man searched for a reliable method of restoring missing teeth; the search has persisted, and several materials and procedures have been tried. Samples of tooth replacement prostheses made from gold wire, ox bone or wood have been found in ancient Egyptian times [1]. In $1000 \mathrm{AD}$, the Chinese developed ceramics [2], which, while not originally intended for tooth replacement, have been used for the purpose of restoring missing teeth ever since.

For several years, man has had an interest in ceramics. Ceramics were one of the most sophisticated materials available to human during the Stone Age, and this material has maintained its significance so far [3]. Additionally, ceramics are perhaps the best materials available for replicating functions and aesthetic qualities of a complex human tooth. Dental ceramics, based upon porcelain, were first used by Alexis Duchâteau to fabricate complete dentures in the late 1700s [4]. In 1900, Land introduced porcelain jacket crowns, which were constructed from feldspathic or aluminous porcelain and were baked on a thin platinum foil [5]. Due to their poor mechanical strength and the difficulty in reproducing precise marginal fit, these jacket crowns often failed, and their use was restricted to anterior teeth [5].

\subsection{Metal Ceramic Restorations}

The metal ceramic technology matured in the 1950s following various adjustments to the key feldspar-quartz-kaolin composition and years of evaluations and trials [3]. This advancement resulted in more reliable metal ceramic restorations. The fabrication of such prostheses takes place by firing porcelain at high temperature to a metal coping that fits a prepared tooth. However, a fracture or cracking of the porcelain layer (veneering) upon cooling was a major problem that often occurred, which was attributed to the thermal expansion incompatibility between the metal coping and the veneering porcelain [5]. This further encouraged research and experiments that led to the development of leucite-containing (high thermal expansion mineral) feldspathic porcelain. This mineral allowed for a better adjustment of the thermal expansion mismatch between metal coping and the veneering porcelain layer [5]. It also played a significant role in placing the veneering porcelain in compression, which favorably provided increased resistance to shattering or fracture. The successful performance and reliability of such restorations have led to substantial improvements 
in alloy substrates and veneering porcelains. Moreover, they have encouraged a widespread acceptance of these restorations [6].

Despite the fact that metal ceramic restorations have been the norm for either single or multiple tooth prostheses [7], certain variables have been highlighted as conceivable limitations of these restorations. For instance, poor aesthetics that resulted from difficulty in producing the required translucency, and unfavorable metal margin visibility, particularly in the anterior teeth and poor biocompatibility, were the most common drawbacks of these restorations [8] [9] [10]. A source of failure of such restorations is delamination that takes place between the porcelain veneer and the underlying metal coping. Moreover, some base metallic components, which are routinely used as reinforcing substructures, may corrode or cause allergic response [11].

\subsection{All-Ceramic Restorations}

There has been a long history of success in restorative dentistry using a combination of metal substructures and ceramic veneer materials. In spite of this, the limitations of such restorations, as well as the need for cautious tooth preparation, have encouraged further improvements in ceramic products and various techniques. Numerous attempts have been made to produce a ceramic system that allows the fabrication of crowns and fixed partial dentures without the use of supplementary metal reinforcing.

Recent revolutions in dental materials fabrication and processing technologies that have taken place in the last two decades have resulted in the development of a wide range of all-ceramic materials. This holds promises for a much wider application of more reliable all-ceramic restorations in both the anterior and posterior segments of the oral cavity [12]. An all-ceramic restoration is essentially fabricated by one of the following two methods: 1 ) the entire restoration is made from low crystalline content and translucent porcelain/ceramic, which is subsequently stained and glazed to achieve the optimal aesthetics; 2) a stronger, but relatively opaque, ceramic core is first fabricated and then veneered with weaker, but more aesthetic, conventional porcelain (veneering material) [13]. The bond between ceramic core and the veneering layer is achieved through the chemical affinity between the two materials [14]. Diminishing the use of the opaque metal substrate resulted in better translucency, which in turn imparted excellent aesthetic features. This advent has provided patients with excellent color features, wear resistance, low thermal conductivity and excellent biocompatibility. Accordingly, the interest in the use of all-ceramic restorations by clinicians and patients has considerably increased.

\section{All-Ceramic Restoration Systems}

There is a wide range of all-ceramic systems that are currently available for the fabrication of single or multiple units' dental restorations. All-ceramic systems can be classified into three main categories [15]: 
- Glass-based ceramics;

- Glass-infiltrated ceramics (In-Ceram groups);

- Non-glass-based (polycrystalline) ceramics.

Despite the superior aesthetics, inertness, and biocompatibility offered by all-ceramic restorations, and the modern advances in the materials science and processing technologies, the clinical application of these types of restorations has been significantly limited by the lack of sufficient strength, fracture toughness and the brittle nature of ceramics [16]. As a result, all-ceramic restorations have had a poor survival rate, particularly when compared to the metal ceramic restorations. In addition, the existence of pores or structural defects, and the intrinsic proliferation of micro-like flaws, defects, or imperfections during processing or chewing have decreased the clinical performance of all-ceramic materials. Consequently, these have hampered their broader use, particularly in the posterior segments [17]. In order to understand and overcome this limitation, it is firstly necessary to understand the concept of fracture mechanics.

\section{Fracture Mechanics}

The role of the mastication forces and resultant stresses that may cause either deformation or fracture of a dental restorative material in the oral cavity is a very important consideration of dental materials science [18]. A fracture is mostly caused by a single-overload event, or multi loaded (fatigue). Fracture mechanics defines the behavior of a material containing a defect or crack to external stress [18]. It provides a basis for predicting the behavior of structural materials containing cracks varying in sizes [19] [20] [21] [22]. Crack propagation and subsequent fracture are the major problems that result in the structural failure of brittle materials.

The fracture is initiated when the stress intensity level at the crack tip $(K)$ exceeds a critical $\left(K_{I C}\right)$. The stress intensity factor is determined by a combination of applied tensile stress $(\sigma)$, crack length $(a)$, and a dimensionless constant $(Y)$ that varies according to the stress mode, crack shape, and fracture test geometry, and is defined as $K=\sigma Y \sqrt{a}$ [23] [24] [25]. The stress intensity factor characterizes the magnitude of the localized stress field in the vicinity of the crack tip.

\section{Brittleness}

It is true that structural materials behave differently under external load (stress). Ceramics are mechanically affected by their brittle nature, which in turn defines their tendency to catastrophic failure when external stresses surpass their elastic limit. While ductile materials, such as metals and alloys, present an appreciable amount of plastic deformation when stressed beyond their elastic limit, brittle materials, such as glasses and ceramics, fail catastrophically without plastic strain (Figure 1(a)) [26]; that is at or near their proportional limit. This is despite the fact that ceramics are brittle materials, but not necessarily weak. However, in many instances, brittle materials are incapable of exhibiting strength 


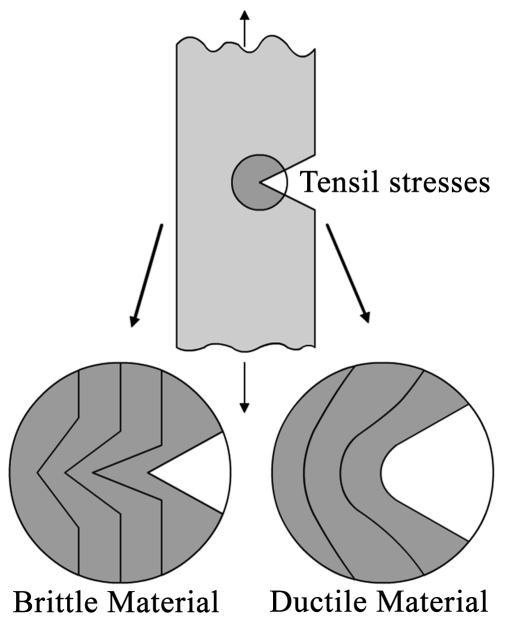

(a)

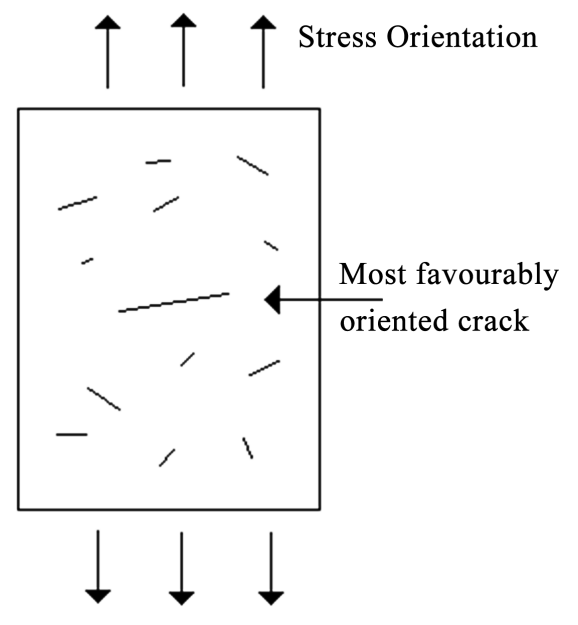

(b)

Figure 1. Illustration of the different behaviors of brittle and ductile materials upon tensile stresses. Brittle materials are unable to minimize the effect of tensile stresses at the crack tip by plastic deformation (a) [26]; schematic illustration of different cracks that can cause fracture in a brittle material stressed by tensile forces (b) [27].

suggested by intrinsic atomic bonding, and hence may fracture at stresses much below their actual strength [24]. Therefore, a liability to fracture will definitely remain a limiting factor in the design of brittle materials submitted to intermittent forces. All-ceramic components are not an exception.

Owing similarity to all brittle materials, all-ceramic restorations fail in tension, because they are unable to absorb a sufficient amount of elastic strain energy prior to fracture. They are also sensitive to micro-like defects that are inherently present within surface or the bulk of ceramic materials, or may grow as a result of thermal, chemical, or mechanical processes. Moreover, cracks may also develop during in-service mastication. These cracks (Figure 1(b) [27] and Figure 2(a)) act as localized stress concentrators, and may lead to a catastrophic failure due to a probable defect-induced fracture. It has been advocated that the clinical failure of restorations made from all-ceramic materials is very often associated with their brittleness, poor mechanical properties, and sensitivity to detrimental cracks [28].

\section{Role of Cracks in Brittle Materials}

In many clinical cases, the failure of brittle materials, such as dental ceramics, is associated with structural defects or flaws [29]. Therefore, when studying the properties of these materials, it is occasionally important to examine the structural elements, and defects that might be present. This allows for a proper understanding of the relation between defects, structural elements and properties. Once this is established, a better understanding of the properties of materials is possible. Usually, the structural investigations are performed at macroscopic or microscopic levels. Understanding the role of the microscopic flaws or defects, such as cracks, is very essential in explaining the behavior of most structural 


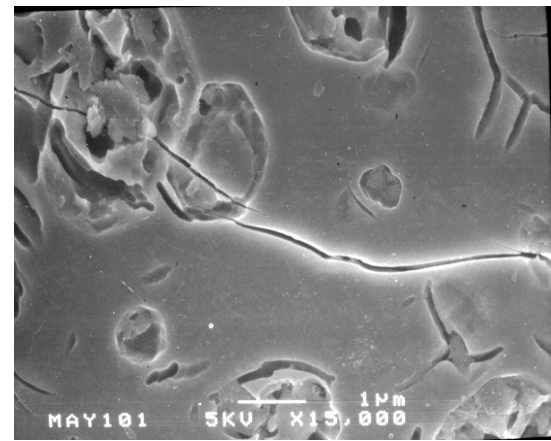

(a)

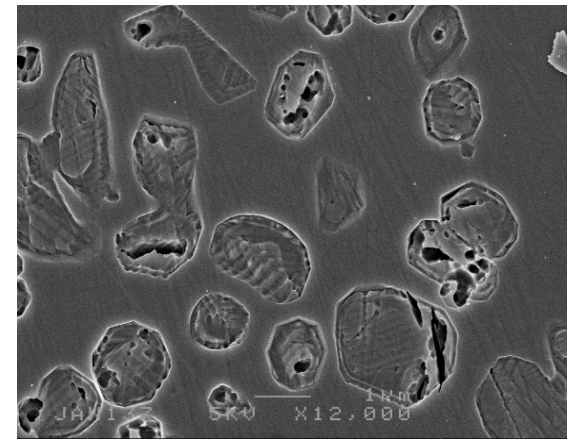

(b)

Figure 2. Detrimental cracks within the glass matrix of a leucite-based glass ceramic material (a); leucite crystals are embedded in the glass matrix of a leucite-based glass ceramic material (b).

materials under load. Crack initiation, orientation and propagation can significantly dictate the mechanical behavior of brittle materials [26] [30]. In fact, the majority of dental ceramics encompasses a minimum of two defect populations: processing defects or scratches, and surface cracks [5] [31]. Hypothetically, the size of a defect's tip is similar to the space among atoms in a structural material. The accumulation of stress at the tip of a flaw can cause localized stress to rise to the factual strength of a material at a relatively low stress magnitude. As a result, a crack is developed when the theoretical strength is surpassed at the flaw's tip and the bond ruptures. Consequently, this leads to crack propagation through the material, if the crack isn't opposed, deflected, or arrested by a hindrance. Ordinarily, this disperses further energy. In such a situation, it should be noted that the type of stress is significantly relevant; tensile stresses at the vicinity of crack tip cannot be reduced in a brittle material. As a result, cracks may propagate, thereby causing an ultimate fracture at low-average tensile stress. This indicates the significant effect of crack sharpness, orientation, distribution, and in particular the size [21]. The crack size is highly influential in this respect. This can be explained on the basis of the stress concentration concept. Most fractures favorably propagate from the largest cracks, assisted by the orientation and the magnitude of the most detrimental forces, tensile stresses.

One of the most essential characteristics of critical cracks in brittle materials is the so-called slow crack growth phenomenon. In fact, cracks can grow slowly and steadily. This may take place even at stresses below the critical level. It takes place in a suitable environment, such as the oral cavity, where liquids, such as water or saliva, are present. It is suggested that this occurs when water molecules react with the crack tip, causing a breakdown of the metal oxide bond with subsequent hydroxides formation. Under mechanical forces, a crack can grow in a slow manner, until it reaches a critical size; that is sufficient to cause fracture. In such a condition, the strength may deteriorate over time, thereby leading to a shorter lifetime of the dental restoration. Therefore, factors such as distribution of crack size, shape, and orientation are extremely crucial in determining the mechanical strength of dental ceramics. 


\section{Mechanical Properties}

The stability of a structural material under mechanical stress is evaluated by assessing its mechanical properties [32]. Plastic deformation or fracture of materials that takes place under applied mechanical forces is significantly affected by the microstructure of materials [33]. For example, the responses of materials to external forces can cause a shape change or disintegration only if these forces are adequately high i.e., above the endurance level. In this instance, the resistance of a material to any structural alteration, either in shape or dimension, is due to the capability of the interatomic forces that override the extrinsic forces [34].

Mechanical properties are a subgroup of physical properties that are determined by the principles of mechanics. Essentially, they delineate the behavior or reaction of a specific structure to the applied external forces [35]. They reveal the elastic or plastic behavior of a structure when force is applied, thereby indicating its capability for a load-bearing application. Mechanical properties are also helpful in identifying and classifying structural materials. The following are the most important mechanical properties that need to be evaluated when structural materials are designed to resist external mechanical forces: 1) elastic modulus; 2) flexural strength; 3) fracture toughness; 4) hardness; and 5) poison's ratio.

\subsection{Elastic Modulus}

The well-known concept of stress and strain is most often used to specify mechanical properties. Stress is the force intensity at any point in a body submitted to a load [36]. Stresses must be defined according to their magnitude and direction [37]. In relation to the direction, they can be classified into three types: 1) tensile stress, which is a load that creates a stretch or elongation of a body; 2) compressive stress, which is the load that tends to shorten or compress a body; and 3) shear stress, which is the resistance to a twisting motion or sliding of one part of a body over another.

Whenever stress is applied, it results in deformation or strain. Strain is a term that describes how a material reacts to stress. Under applied force, strain describes the approximate deformation in shape and size of either elastic or plastic materials [36]. In response to a mechanical force, materials undergo a change in dimension; this is called deformation. When a material reverts to its original size and shape upon stress removal, the deformation is called elastic. If a permanent change in the shape is caused by the removal of the stress, the deformation is called plastic [38].

Elasticity, also termed as Young's modulus or Elastic modulus, represents the stiffness of a material within the elastic range when tensile or compressive forces are applied [39]. It is also an indication of the amount of reversible deformation that will occur in a structure when a load is applied to it. The interatomic or intermolecular forces of a material determine its elastic properties. Owing to the fact that this property is strongly dictated by these forces, a material will have the same elastic modulus value if a compressive or tensile force is applied. Moreover, it is independent of any heat or mechanical treatments [4]. 
The knowledge of the elastic modulus is clinically relevant, because it may assist in the selection of a restorative material with more similarly deformable properties to those of the material it is replacing. For example, when a restorative material has comparable elastic properties to those of the tooth structure, the differential deflection, which normally occurs at the tooth restoration interface and is considered harmful to marginal bonding, can be decreased. In a dental restoration, such as all-ceramic single or multiple units, a high Elastic modulus is often required. It is desirable that a material undergoes limited deflection on loading and returns to its original shape after it has been stressed. It has been reported that increasing the elastic modulus of a supporting core structure of a dental core, made from all-ceramic material, might be a way of improving the ability of fracture resistance of all-ceramic dental materials [40] [41] [42]. Accordingly, the elastic modulus might be a basis for selection of core made out of these materials.

\subsection{Hardness}

Hardness is a frequently reported mechanical property that results from the interaction of other mechanical properties, such as strength, proportional limit, and ductility [43]. Despite the difficulty in defining this term, it is widely known as a measure of the resistance to the permanent surface indentation or penetration [16] [44].

Since all-ceramic materials are highly sensitive to flaws or defects, hard materials should have the potential of resisting surface notches, scratches, or flaws, from which some detrimental cracks are initiated. Therefore, hardness is a very significant mechanical property, especially when brittle materials are mechanically assessed. During mastication, the in-service resistance to scratching might be dictated by the surface hardness. Hardness also indicates the ease of grinding, finishing, and polishing of a dental restoration during laboratory fabrication steps. In addition, the significance of measuring hardness, when all-ceramic restoration is the treatment choice, is that it may delineate the abrasiveness (wear) of a material to which the natural dentition may be submitted [16]. Hence, similar hardness characteristics of an all-ceramic restoration to that of the enamel might minimize the harmful effect of abrasion during contact; however, this is significantly affected by the polishing and/or glazing status of the ceramic material [45] [46] [47]. Various types of all-ceramic dental materials are used for core constructions. These cores are covered with thermally compatible porcelain veneering material. This would render the effect of core's hardness inconsequential. This is applicable even though dentition can come into direct touch with core materials, in non-aesthetic areas, where the bulk of core material is designed to be thicker, for further strength enhancement, in areas submitted to high tensile forces, such as the connector area.

\subsection{Strength}

The maximum amount of stress applied on a material leading to fracture, and 
subsequent structural failure is known as strength [48]. Unlike the elastic modulus, it is a measure of forces over a specific region of a stressed structure rather than attraction between atoms [3]. It is an important mechanical property that determines the performance of brittle materials [49] [50]. However, microcracks and processing defects that inherently grow during thermal or mechanical processes can significantly influence strength measurement [51] [52]. Therefore, strength is considered a conditional property. Furthermore, an appraisal of strength is significantly influenced by a number of variables, some of which include the following: 1) testing design; 2) specimen geometry; 3) polishing procedures and testing environments [53] [54].

Brittle materials, like dental ceramics, are much stronger in compression than in tension. In addition, since ceramics are unable to alleviate tensile stresses at the tip of microstructural defects, such as cracks, through inelastic deformation, they are substantially weaker in tension than in compression. This also explains why dental restorations normally fail in areas of tensile stresses [3] [55]. Strength of brittle materials is usually assessed using flexural techniques; these techniques are generally easier to conduct than pure tensile techniques [56].

\section{Weibull Modulus}

The statistical measure of strength is expressed by the mean strength with standard deviation and coefficient of variation. However, ceramics usually have a large variation in strength as a result of the effect of different sizes of internal processing flaws, which makes the results unpredictable sometimes. Hence, it is arguable whether the mean strength of the brittle ceramic materials is reliable and can portray their actual strength [57] [58].

The most important reason of fracture is the size and shape of a critical pre-existing crack or flaw within the area of maximum tensile stresses. The larger the crack or pre-existing defect size, the lower the tensile strength at which the materials fracture [51] [59]. In addition, the other two influential factors to be considered during the brittle testing are the size and shape of specimens. For example, large samples are more likely to contain larger flaws than those in small samples. As a result, the largest flaw is more likely to propagate and the sample fails at lower stresses. This indicates the importance of the sample volume, which is directly relevant to the fracture strength of brittle materials (volume dependence of strength) [59]. The influence of specimen volume was incorporated into strength appraisal when Weibull, a Swedish physicist, proposed the concept of survival probability $P_{s}\left(V_{0}\right)$ instead of the common average strength, to describe the strength of brittle materials. The survival probability of samples at an applied stress $(\sigma)$ having the identical volume $\left(V_{0}\right)$ can be stated by the following equation:

$$
P_{\mathrm{s}}\left(V_{0}\right)=\exp \left\{-\left(\sigma / \sigma_{0}\right)^{m}\right\}
$$

where $\sigma_{0}$ and $m$ are constants and $\sigma$ is the applied tensile stress [60] [61]. When the applied tensile stress is set equal to zero, the previous expression results in $P_{s}\left(V_{0}\right)=1$, and all samples survive. As the stress increases, the samples fail, and 
$P_{\mathrm{s}}\left(V_{0}\right)$ becomes consequently smaller. At $\sigma=\infty$, all the samples break and $P_{\mathrm{s}}\left(V_{0}\right)$ $=0$. If the $\sigma$ is set equal to $\sigma_{0}$ in the formula the result is $P_{\mathrm{s}}\left(V_{0}\right)=1 / \mathrm{e}=0.37$. So, $\sigma_{0}$ is the stress that allows $37 \%$ of the samples to survive. The exponent constant $m$ indicates how quickly the strength falls, as $\sigma_{0}$ is approached. This is called the Weibull modulus [18] [59]. The Weibull modulus characterizes the distribution or variability of strength data. The lower the value of $m$, the greater the variability of the strength is, whereas higher $m$ values correspond to the uniform distribution of remarkably consistent flaws with narrower strength variations [58] [59] [60]. The previous in vitro studies on strength of dental ceramics reported that the Weibull modulus $(m)$ ranged from 5 to 15 [29].

\subsection{Fracture Toughness}

Fracture toughness is the critical stress intensity level in a loaded body at which a given flaw starts growing [16] [62]. It indicates the ability of a material to resist rapid crack propagation and its consequent catastrophic failure [63]. Fracture toughness is considered an intrinsic property and an appropriate parameter that can indicate the structural performance of brittle materials. Unlike strength, it is a genuine characterization of a mechanical behavior, as it is normally independent of the size or density of surface flaws [64] [65] [66].

Measurement of the fracture toughness of a specific ceramic material not only imparts insight into the ability of a material to resist crack propagation, but also influences the thermal shock resistance [67]. Another important feature of fracture toughness is its ability to indicate a material's serviceability in the oral cavity [50] [68]. Furthermore, when studying fracture behavior and toughening mechanisms of brittle materials, the fracture toughness data often produce useful information concerning the role played by the crystalline phase within the glass matrix.

\subsection{Poisson's Ratio ( $v)$}

Axial loading in tensile or compressive mode is accompanied by a simultaneous axial and lateral strain. If a material is under tensile load, it elongates in the direction of the load, and there is a reduction in the cross section area. In case of the compressive load, there is an increase in the cross section area [4]. Poisson's ratio is the ratio of the lateral to the axial strain within the elastic range. This mechanical property is related to the nature and symmetry of the interatomic bonding forces [3]. Most engineering materials have Poisson's ratio values of approximately 0.3 [3]. Brittle materials exhibit no permanent reduction in cross section during the tensile loads, whereas the ductile materials display a considerable reduction in the cross sectional areas [4].

\section{Discussion}

\subsection{Appraisal of Mechanical Properties}

During the last two decades, dental restorations made from all-ceramic materials 
have generated considerable interest owing to their excellent aesthetic properties and biocompatibility. Hence, the use of these restorations has been rapidly increasing. However, the inherent brittleness of these materials along with severe sensitivity to microcrack-like defects have limited their broader use and restricted their application to fairly low stress-bearing areas. The mechanical properties of these brittle materials are crucial and must be considered when these materials are chosen for bear loading, such as dental restorations, fabricated from all-ceramic materials.

The science of engineering materials identified flexural strength, fracture toughness, Young's modulus, hardness and Poisson's ratio as important mechanical properties that delineate the behavior of brittle materials, such as all-ceramic dental restorations. All-ceramic materials can be used for the construction of inlays, onlays, crowns and fixed partial denture. In the oral cavity, where the mastication regularity creates different modes of intermittent forces, some of which are tensile, compressive, and complex stresses, these materials are stressed and may fracture. The appraisal of the mechanical properties of these materials provides useful information for selecting the appropriate material and application technique. It is true that the clinical applications of all-ceramic restorations should be defined through long-term clinical studies. However, the conducting of clinical studies is often associated with a number of difficulties related to, for instance, time, costs, number of patients, and influence of variables. Moreover, there is a scarcity of preclinical studies on the most recent generation of dental restorative materials prior to their wide use. This always creates a great emphasis on mechanical properties to define the clinical indications as well as the limitations of these materials. The clinical failure of restorations made from all-ceramic materials is very often associated with their brittleness and poor mechanical properties. The efforts to improve the longevity of dental ceramic materials have been directed towards improving their mechanical properties, especially strength and fracture toughness [69]. Each of these mechanical properties has a unique and standardized method that is used by researchers or engineers. When comparing the mechanical properties of different all-ceramic materials, they must be assessed under the same conditions and also the same testing methodology because different testing methodologies can impart different mechanical values. Accordingly, the values obtained from studies conducted with different protocols and/or different test methods are not comparable.

\subsection{Microstructure and Toughening Mechanisms}

Although the relation between the mechanical properties of all-ceramic materials and its clinical performance is influenced by several variables, some of these properties, namely strength and fracture toughness, have often been the first parameters investigated. In order to understand the mechanical behavior of all-ceramic materials, it is necessary to identify their essential microstructural features. The microstructure of most glass ceramics is composed of two main 
components; the low modulus glass matrix and the reinforcing components, the crystalline part (Figure 2(b)). Some other types lack the glass portion, named polycrystalline materials; these types are mainly composed of high purity of crystalline components (Figure 3(a)). In both these types, it is speculated that different types of interactions take place between the material's microstructure and microstructural flaws or defects, such as cracks, during the mechanical stressing. This interaction imparts fracture resistance of a ceramic material; it is called toughening mechanism. Several mechanisms for toughening and strengthening ceramic materials have been proposed [70] [71] [72]. These mechanisms include the following: 1) crack-tip interaction; 2) crack-tip shielding; 3)-and crack bridging. All of these mechanisms aim to intensify the energy required for crack propagation in various methods. The crack-tip interaction mechanism occurs when an impediment within a microstructure, such as crystals, obstructs fracture propagation, thereby causing the crack motion to reorient and, as a result, requires more energy for crack extension (Figure 3(b)). When the stresses at the vicinity of crack tip region are reduced by either 1) microcrack toughening or by 2) transformation toughening; this is known as the crack-tip shieling mechanism. In multiphase structures, and when microstructure is essentially associated with residual stress, the microcrack toughening mechanism is dominant. The residual stresses are more likely to develop in areas with a thermal expansion anisotropy, in materials with polycrystalline structure, where elongated crystals and/or thermal expansion or elastic incompatibility in polyphase materials and/or in transforming materials. It is believed that the localized formed compressive stresses near the crack tip are capable of resisting the tensile forces, which forces the cracks to move forward. The transformation toughening mechanism occurs in tetragonal zirconia-based materials. This process is inherent with a $4 \%$ volume expansion and consequent compressive stresses at the region surrounding the crack tip. In fiber-reinforced or rod-like crystals containing materials, a crack bridging mechanism is expected when a second phase acts like a ligament to prevent the crack sides to open.

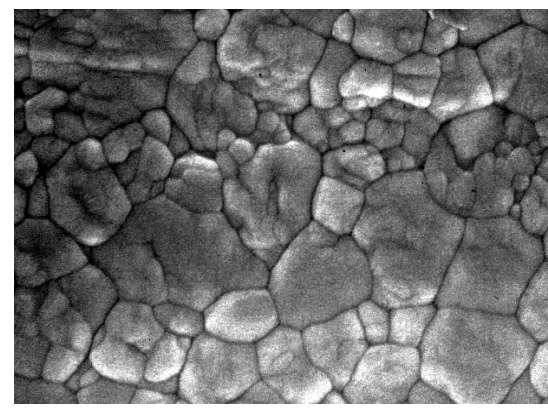

(a)

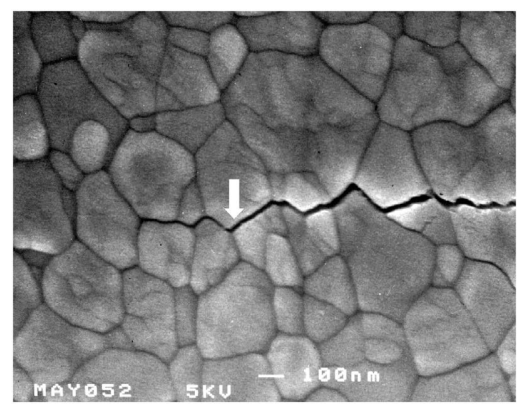

(b)

Figure 3. Densely packed fine $\mathrm{ZrO}_{2}$ crystals, representing the microstructure of zirconium oxide based all-ceramic material (polycrystalline type) (a); crack propagation in the microstructure of $\mathrm{ZrO}_{2}$ based all-ceramic material (intergranular crack pattern), crack-microstructure interaction; the crack tip is arrowed (b). 


\subsection{Role of Crystalline Portion}

Since all-ceramic materials rely on their crystalline components (Figure 4(a) and Figure 4(b)) (Figure 5(a) and Figure 5(b)), in addition to enhancing their mechanical properties, most mechanical properties of all-ceramic materials, especially strength, fracture toughness, and elasticity, are significantly determined by the type, amount, size, and orientation (Figure 6(a) and Figure 6(b)) of the reinforcing crystalline components [62] [73] [74] [75] [76]. Higher the reinforcing crystalline components, the more improved are the mechanical properties and vice versa. This explains the significant difference in the values of mechanical properties values among different all-ceramic systems. It is worth noting that an increase in the crystalline content may also result in an increase of the opacity [17] [77]. Consequently, the aesthetic outcome of restorations that are constructed from all-ceramic systems that are based on highly crystalline contents, such as the monolithic all-ceramic systems, may be inferior compared to those made from the bi-layered all-ceramics. In this case, it is recommended that monolithic all-ceramic systems are used in areas where aesthetic requirements are less critical, such as posterior teeth.

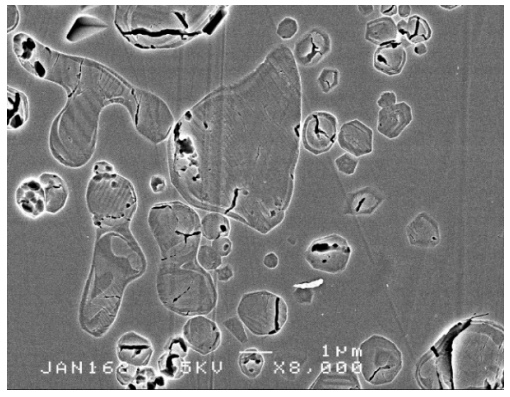

(a)

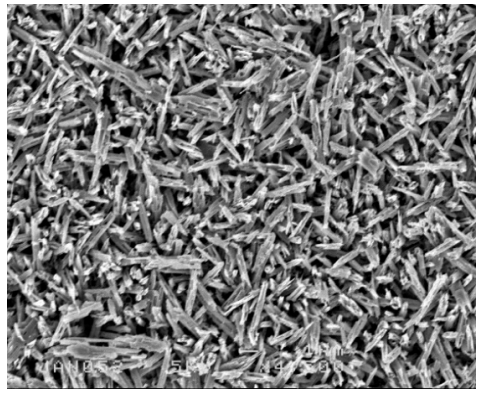

(b)

Figure 4. Irregular shaped and spherical leucite crystals of different sizes embedded in glassy matrix of a leucite-based glass ceramic material (a); densely packed lithium disilicate crystals within the glass matrix with different directions in a lithium-based glass ceramic material (b).

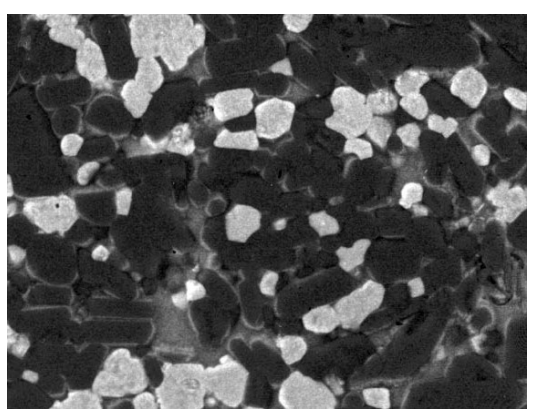

(a)

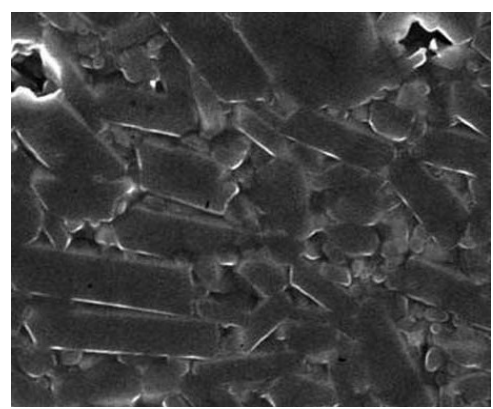

(b)

Figure 5. Microstructure of In-Ceram Zirconia, where clusters of white grains particles $\left(\mathrm{ZrO}_{2}\right.$, zirconium oxide crystals) and dark grey grains particles $\left(\mathrm{Al}_{2} \mathrm{O}_{3}\right.$, aluminum oxide crystals) are embedded into a glassy matrix (a); micrographs of In-Ceram Alumina, where elongated and spherical $\mathrm{Al}_{2} \mathrm{O}_{3}$ crystals are distributed in a glass matrix (b). 


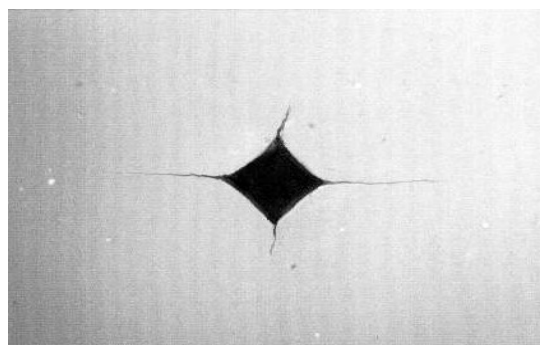

(a)

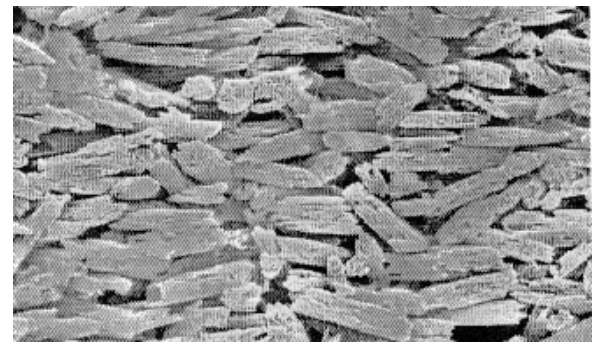

(b)

Figure 6. Cracks of dissimilar length emanating from the corners of an indentation (a), with their orientation as well as length being influenced by the lithium disilicate crystals' alignment (b).

\subsection{Mechanical Properties of Some Currently Used All-Ceramics Systems}

In the literature, in vitro studies provided numerous mechanical properties data that assist clinicians to choose among various all-ceramic systems, for different clinical situations. Glass-based ceramics are partially polycrystalline materials known as fine-grained ceramics [78]. The percentage of the reinforcing particles (crystalline portion), such as in leucite or lithium disilicate glass ceramic systems, ranges from 45 to 70 vol\%. The flexural strength and fracture toughness of these all-ceramic systems range from 120 to $500 \mathrm{MPa}$, and from 1.3 to 2.5 $\mathrm{MPa} \cdot \mathrm{m}^{1 / 2}$, respectively [15] [16] [48] [62]. Some of the most representative all-ceramic systems (glass based-ceramics) include the following: IPS Empress Aesthetic (Ivoclar Vivadent), Optec OPC (Jeneric Pentron), IPS e.max Press, IPS e.max CAD (Ivoclar Vivadent), and 3G (Jeneric Pentron). They can be used as single units, such as inlays, onlays, veneers, and crowns. Higher strength systems such as those based on lithium disilicate can be used as 3-unit FPDs up to the premolar area.

Another group of all-ceramic systems, which is based on particles of alumina, zirconia, or magnesia, is known as In-Ceram group (Vita Zahnfabrik, Bad Säckingen, Germany). They are infiltrated with glass during the fabrication processing to attain their final strength and fracture toughness. Therefore, they are considered glass-based ceramics. The volume of fraction of these all-ceramic systems can reach up to $70 \%$ of pure alumina particles as in case of In-Ceram Alumina, or a mixture of approximately the same percentage of alumina and zirconia, as in case of In-Ceram Zirconia, and a mixture of alumina an magnesia, as in case of In-Ceram Spinell. Their flexural strength and fracture toughness range from 350 to $600 \mathrm{MPa}$, and from 3 to $4.9 \mathrm{MPa} \cdot \mathrm{m}^{1 / 2}$, respectively [18] [74] [79].

High strength polycrystalline all-ceramic materials, such as those based on high purity of either zirconium oxide or aluminum oxide may contain up to $99 \%$ of the reinforcing crystalline components [16] [80]. This high percentage of the crystalline particles results in opacity and less translucency, compared with the optical features offered by the glass-based ceramic systems. Polycrystal- 
line all-ceramic materials are consistently stronger and tougher than all other all-ceramic systems. For example, zirconia-based systems have flexural strength that ranges from 800 to $1500 \mathrm{MPa}$ and fracture toughness up to $8 \mathrm{MPa} \cdot \mathrm{m}^{1 / 2}$ [16] [74] [81] [82]. The flexural strength of Alumina-based systems ranges from 600 to $700 \mathrm{MPa}$, [69] [83] [84]; the fracture toughness is in the range of $4 \mathrm{MPa} \cdot \mathrm{m}^{1 / 2}$ to $4.5 \mathrm{MPa} \cdot \mathrm{m}^{1 / 2}$ [18] [62] [76].

As seen from the above mechanical properties' values, high crystalline content, that exceeds $90 \%$, predominantly found among polycrystalline all-ceramic materials, is favorably strong and sufficiently tough to be used as core materials for the fabrication of PFBs, where aesthetic qualities are not of high concern. Whereas all-ceramic systems that contain from $60 \%$ to $70 \%$ of crystalline reinforcing particles are suitable for lower stress bearing areas, up to the premolar areas. in such crystalline composition, these systems yet maintain good translucency and offer a reasonable trade-off between mechanical properties and aesthetic appeal. The combination of these characteristics could be useful in resolving a variety of clinical conditions.

\subsection{Factors Affecting the Intrinsic Mechanical Properties}

Among variables that genuinely affect the intrinsic mechanical properties of all-ceramic restorations is the fabrication procedure and possible adjustments that take place during laboratory or clinical chairside processes necessary for better fixture as well as right occlusion. Subcritical cracks or even major defects (Figure 7(a)), are more likely to occur as a result of such treatments. Upon clinical loading and/or presence of moisture, such defects may initiate fracture, which eventually leads to catastrophic failure. In addition, rough areas, formed during finishing, polishing or grinding, along with surface pores (Figure 7(b)) may result in a variety of stress concentrations, from which mechanical properties can be negatively influenced [85] [86]. Furthermore, due to the improved physical hardness of various ceramic materials, surface polishing is usually a difficult task and time consuming. In addition, diminishing the surface detrimental

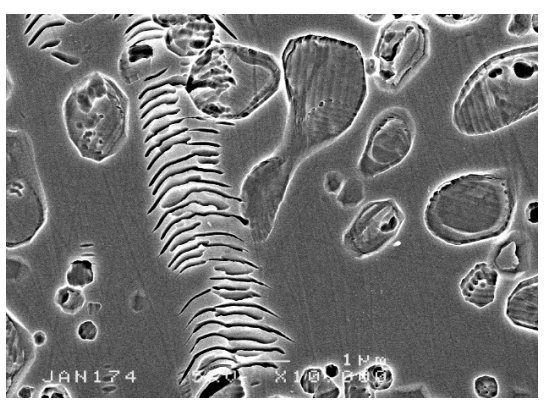

(a)

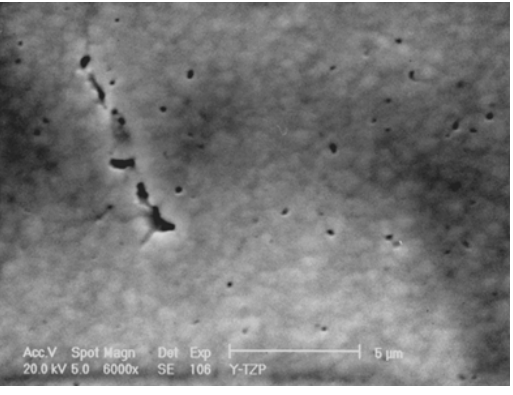

(b)

Figure 7. The microstructure of a leucite-based glass ceramic material, showing leucite crystals and areas of severe glass cracking and damage, resulting from a sliding deformation and damage of some particles of $\mathrm{SiC}$ paper during processing procedures, such as finishing or polishing (a); spherical and irregular shaped pores at the surface of a zirconium oxide based all-ceramic material (b). 
microcracks is challenging as well. Therefore, considering the skills of individual laboratory dental technologists as well as following the manufacturer's instructions for a given dental material are necessary requirements and can lead to a better clinical performance of the all-ceramic materials.

In addition, clinicians' understanding of the brittle nature of ceramics and its sensitivity to some clinical treatments is essential in avoiding any of detrimental consequences on the mechanical properties.

\section{Conclusions}

The knowledge of the mechanical properties of different systems can be very helpful for clinicians to choose among various product systems, especially when comparison takes place between former formulations and modern generations. Several all-ceramic dental products that can meet different treatment requirements of various clinical conditions are currently available in the dental market. In addition, a wide variety of previous in vitro studies provide a wide range of values for the mechanical properties of all-ceramic materials. These studies indicated the significance of several factors that can dictate the mechanical properties of all-ceramic restorations, some of which are related to crystalline content, type, shape, orientation, and toughening mechanisms. Mechanical properties can also be optimized by a suitable design of restoration, faultless processing steps, precise compliance for manufacturers' recommendation, and also choosing the proper all-ceramic material according to the clinical situation.

Despite the fact that the mechanical properties are not necessarily representative of the actual clinical survival or success rate of all-ceramic dental restorations, it is becoming widely acknowledged among engineers, researchers, and clinicians that the lifetime of all-ceramic restorations can significantly be improved by superior mechanical properties.

\section{Acknowledgements}

The author is highly grateful to the faculty of dentistry, University of Najran, KSA, and would like to acknowledge Dr. Abdu Abdulrazak, University of Najran, and Professor Michael Vincent Swain, University of Sydney, for the critical editing and revising of the manuscript.

\section{Author Contribution}

The author confirms sole responsibility for study conception and design, data collection, and manuscript preparation.

\section{Conflicts of Interest}

The author declares that the work documented in this scientific article is not recognized for any conflicting financial interests and/or personal connections.

\section{References}

[1] Ananth, H., Kundapur, V., Mohammed, H.S., Anand, M., Amarnath, G.S. and 
Mankar, S. (2015) A Review on Biomaterials in Dental Implantology. International Journal of Biomedical Science, 11, 113-120.

[2] Chu, S. and Ahmad, I. (2005) A Historical Perspective of Synthetic Ceramic and Traditional Feldspathic Porcelain. Practical Procedures and Aesthetic Dentistry, 17, 593-598.

[3] Anusavice, K.J., Phillips, R.W., Shen, C. and Rawls, H.R. (2013) Phillips' Science of Dental Materials. 18th Edition, Elsevier/Saunders, St. Louis.

[4] Craig, R.G. and Powers, J.M. (2018) Restorative Dental Materials. 14th Edition, Mosby, St. Louis.

[5] Hamza, T.A. and Sherif, R.M. (2019) Fracture Resistance of Monolithic Glass-Ceramics versus Bilayered Zirconia-Based Restorations. Journal of Prosthodontics, 28, e259-e264. https://doi.org/10.1111/jopr.12684

[6] Zarone, F., Di Mauro, M.I., Ausiello, P., Ruggiero, G. and Sorrentino, R. (2019) Current Status on Lithium Disilicate and Zirconia: A Narrative Review. BMC Oral Health, 4, Article No. 134. https://doi.org/10.1186/s12903-019-0838-x

[7] Zhang, Y. and Kelly, J.R. (2017) Dental Ceramics for Restoration and Metal Veneering. Dental Clinics of North America, 4, 797-819. https://doi.org/10.1016/j.cden.2017.06.005

[8] Stona, D., Burnett, L.H., Mota, E.G. and Spohr, A.M. (2015) Fracture Resistance of Computer-Aided Design and Computer-Aided Manufacturing Ceramic Crowns Cemented on Solid Abutments. The Journal of the American Dental Association, 146, 501-507. https://doi.org/10.1016/j.adaj.2015.02.012

[9] Daou, E.E. (2015) Esthetic Prosthetic Restorations: Reliability and Effects on Antagonist Dentition. The Open Dentistry Journal, 31, 473-481. https://doi.org/10.2174/1874210601509010473

[10] Belkhode, V.M., Nimonkar, S.V., Godbole, S.R., Nimonkar, P., Sathe, S. and Borle, A. (2019) Evaluation of the Effect of Different Surface Treatments on the Bond Strength of Non-Precious Alloy-Ceramic Interface: An SEM Study. Journal of Dental Research Dental Clinics Dental Prospects, 13, 200-207. https://doi.org/10.15171/joddd.2019.031

[11] Eliaz, N. (2019) Corrosion of Metallic Biomaterials: A Review. Materials (Basel), 28, 407. https://doi.org/10.3390/ma12030407

[12] Tezulas, E., Yildiz, C., Kucuk, C. and Kahramanoglu, E. (2019) Current Status of Zirconia-Based All-Ceramic Restorations Fabricated by the Digital Veneering Technique: A Comprehensive Review. International Journal of Computerized Dentistry, 22, 217-230.

[13] Miyazaki, T. and Hotta, Y. (2011) CAD/CAM Systems Available for the Fabrication of Crown and Bridge Restorations. Australian Dental Journal, 56, 97-106. https://doi.org/10.1111/j.1834-7819.2010.01300.x

[14] Rashid, H., Sheikh, Z., Misbahuddin, S., Kazmi, M.R., Qureshi, S. and Uddin, M.Z. (2016) Advancements in All-Ceramics for Dental Restorations and Their Effect on the Wear of Opposing Dentition. European Journal of Dentistry, 10, 583-588. https://doi.org/10.4103/1305-7456.195170

[15] Tian, T., Tsoi, J.K., Matinlinna, J.P. and Burrow, M.F. (2014) Aspects of Bonding between Resin Luting Cements and Glass Ceramic Materials. Dental Materials, 30, 147-162. https://doi.org/10.1016/j.dental.2014.01.017

[16] Warreth, A. and Elkareimi, Y. (2020) All-Ceramic Restorations: A Review of the Literature. The Saudi Dental Journal, 32, 365-372. 
https://doi.org/10.1016/j.sdentj.2020.05.004

[17] Albakry, M., Guazzato, M. and Swain, M.V. (2003) Fracture Toughness and Hardness Evaluation of Three Pressable All-Ceramic Dental Materials. Journal of Dentistry, 31, 181-188. https://doi.org/10.1016/S0300-5712(03)00025-3

[18] Guazzato, M., Albakry, M. and Swain, M.V. and Ironside, J. (2002) Mechanical Properties of In-Ceram Alumina and In-Ceram Zirconia. International Journal of Prosthodontics, 15, 339-346.

[19] Ameh, E.S. (2020) Consolidated Derivation of Fracture Mechanics Parameters and Fatigue Theoretical Evolution Models: Basic Review. SN Applied Sciences, 2, Article No. 1800. https://doi.org/10.1007/s42452-020-03563-8

[20] Anderson, T.L. (2017) Fracture Mechanics: Fundamentals and Applications. Fourth Edition, CRC Press, Boca Raton.

[21] Brochard, L., Souguir, S. and Sab, K. (2019) Scaling of Brittle Failure: Strength Versus Toughness. International Journal of Fracture, 210, 153-166.

https://doi.org/10.1007/s10704-018-0268-9

[22] Bottlang, M., Schemitsch, C.E., Nauth, A., Routt, M., Egol, K.A., Cook, G.E. and Schemitsch, E.H. (2015) Biomechanical Concepts for Fracture Fixation. Journal of Orthopaedic Trauma, 12, S28-S33. https://doi.org/10.1097/BOT.0000000000000467

[23] Cotterell, B. and Mai, Y.W. (1996) Fracture Mechanics of Cementitious Materials: Glasgow G64 2NZ. Blackie Academic \& Professional, London.

https://doi.org/10.1201/9781482269338

[24] Stawarczyk, B., Liebermann, A., Rosentritt, M., Povel, H., Eichberger, M. and Lümkemann, N. (2020) Flexural Strength and Fracture Toughness of Two Different Lithium Disilicate Ceramics. Dental Materials Journal, 31, 302-308. https://doi.org/10.4012/dmj.2019-045

[25] Green, D.J. (1998) An Introduction to the Mechanical Properties of Ceramics. University Press, Cambridge. https://doi.org/10.1017/CBO9780511623103

[26] Wachtman, J.R. (1996) Mechanical Properties of Ceramics. John Wiley \& Sons, New York.

[27] O’Brien, W.J. (2002) Dental Materials and Their Selection. 3rd Edition, Quintessence Publishing Co. Inc., Chicago.

[28] Ashby, M.F. and Jones D.R.H. (1999) Engineering Materials 2. An Introduction to Microstructures, Processing \& Design. Butterworth Heinemann, Oxford.

[29] Rekow, E.D., Silva, N.R., Coelho, P.G., Zhang, Y., Guess, P. and Thompson, V.P. (2011) Performance of Dental Ceramics: Challenges for Improvements. Journal of Dental Research, 90, 937-952. https://doi.org/10.1177/0022034510391795

[30] Gonzaga, C.C., Cesar, P.F., Miranda, W.G. and Yoshimura, H.N. (2011) Slow Crack Growth and Reliability of Dental Ceramics. Dental Materials, 27, 394-406. https://doi.org/10.1016/j.dental.2010.10.025

[31] Li, J., Huang, Q. and Ren, X. (2013) Dynamic Initiation and Propagation of Multiple Cracks in Brittle Materials. Materials (Basel), 6, 3241-3253. https://doi.org/10.3390/ma6083241

[32] Sanchez, L.E.A., Oliveira, J.F.G. and Coelho, R.T. (2005) Detection of Cracks in Scratching Tests in Ceramic Materials through Acoustic Emission. Proceedings of the Institution of Mechanical Engineers, Part B: Journal of Engineering Manufacture, 219, 685-693. https://doi.org/10.1243/095440505X32616

[33] Wang, L., D’Alpino, P.H., Lopes, L.G. and Pereira, J.C. (2003) Mechanical Properties of Dental Restorative Materials: Relative Contribution of Laboratory Tests. 
Journal of Applied Oral Science, 11, 162-167. https://doi.org/10.1590/S1678-77572003000300002

[34] Hallmann, L., Ulmer, P. and Kern, M. (2018) Effect of Microstructure on the Mechanical Properties of Lithium Disilicate Glass-Ceramics. Journal of the Mechanical Behavior of Biomedical Materials, 82, 355-370. https://doi.org/10.1016/j.jmbbm.2018.02.032

[35] Finnis, M. (2004) Interatomic Forces in Materials. Progress in Materials Science, 49, 1-18. https://doi.org/10.1016/S0079-6425(03)00018-5

[36] Murugan, S.S. (2020) Mechanical Properties of Materials: Definition, Testing and Application. International Journal of Modern Studies in Mechanical Engineering, 6, 28-38.

[37] Schlenker, B.R. (1986) Introduction to Materials Science. SI Edition, Jacaranda Press, Sydney.

[38] Anusavice, K.J. (1996) Philip's Science of Dental Materials. 10th Edition, WB Saunders Company, Philadelphia.

[39] Schaffer, J.P., Saxena, A., Antolovich, S.D., Sanders, J. and Warner, S.P. (1995) The Science and Design of Engineering Materials. Irwin, Inc., Chicago.

[40] Baino, F. and Fiume, E. (2109) Elastic Mechanical Properties of 45S5-Based Bioactive Glass-Ceramic Scaffolds. Materials (Basel), 4, 3244.

https://doi.org/10.3390/ma12193244

[41] Kolednik, O., Predan, J., Fischer, F.D. and Fratzl, P. (2014) Improvements of Strength and Fracture Resistance by Spatial Material Property Variations. Acta Materialia, 68, 279-294. https://doi.org/10.1016/j.actamat.2014.01.034

[42] Scherrer, S.S. and de Rijk, W.G. (1993) The Fracture Strength of All-Ceramic Crowns on Supporting Structures with Different Elastic Moduli. International Journal of Prosthodontics, 6, 462-467.

[43] Alshabib, A., Silikas, N. and Watts, D.C. (2019) Hardness and Fracture Toughness of Resin-Composite Materials with and without Fibers. Dental Materials, 35, 1194-1203. https://doi.org/10.1016/j.dental.2019.05.017

[44] Malzbender, J. (2003) Comments on Hardness Definitions. Journal of the European Ceramic Society, 23, 1355-1359. https://doi.org/10.1016/S0955-2219(02)00354-0

[45] Elmaria, A., Goldstein, G., Vijayaraghavan, T., Legeros, R.Z. and Hittelman, E.L. (2006) An Evaluation of Wear When Enamel Is Opposed by Various Ceramic Materials and Gold. Journal of Prosthetic Dentistry, 96, 345-353.

https://doi.org/10.1016/j.prosdent.2006.09.002

[46] Olivera, A.B., Matson, E. and Marques, M.M. (2006) The Effect of Glazed and Polished Ceramics on Human Enamel Wear. International Journal of Prosthodontics, 19, 547-548.

[47] Schuh, C., Kinast, E.J., Mezzomo, E. and Kapczinski, M.P. (2005) Effect of Glazed and Polished Surface Finishes on the Friction Coefficient of Two Low-Fusing Ceramics. Journal of Prosthetic Dentistry, 93, 245-252. https://doi.org/10.1016/j.prosdent.2004.12.010

[48] Albakry, M., Guazzato, M. and Swain, M.V. (2003) Biaxial Flexural Strength, Elastic Moduli, and X-Ray Diffraction Characterization of Three Pressable All-Ceramic Materials. Journal of Prosthetic Dentistry, 89, 374-380.

https://doi.org/10.1067/mpr.2003.42

[49] Sen, N. and Us, Y.O. (2018) Mechanical and Optical Properties of Monolithic CAD-CAM Restorative Materials. Journal of Prosthetic Dentistry, 119, 593-599. 
https://doi.org/10.1016/j.prosdent.2017.06.012

[50] Gorman, C.M., Horgan, K., Dollard, R.P. and Stanton, K.T. (2014) Effects of Repeated Processing on the Strength and Microstructure of a Heat-Pressed Dental Ceramic. Journal of Prosthetic Dentistry, 112, 1370-1376.

https://doi.org/10.1016/j.prosdent.2014.06.015

[51] Taskonak, B., Griggs, J.A., Mecholsky, J.J. and Yan, J.H. (2008) Analysis of Subcritical Crack Growth in Dental Ceramics Using Fracture Mechanics and Fractography. Dental Materials, 24, 700-707. https://doi.org/10.1016/j.dental.2007.08.001

[52] Turon-Vinas, M. and Anglada, M. (2018) Strength and Fracture Toughness of Zirconia Dental Ceramics. Dental Materials, 34, 365-375.

https://doi.org/10.1016/j.dental.2017.12.007

[53] Evans, A.G. (1982) Structural Reliability: A Processing-Dependent Phenomenon. Journal of the American Ceramic Society, 65, 127-137. https://doi.org/10.1111/j.1151-2916.1982.tb10380.x

[54] Ban, S. and Anusavice, K.J. (1990) Influence of Test Method on Failure Stress of Brittle Dental Materials. Journal of Dental Research, 69, 1791-1799.

https://doi.org/10.1177/00220345900690120201

[55] Cesca, R., Colombo, V., Ernst, B., Gallo, L.M. and Özcan, M. (2020) Tensile Strength and Failure Types of Direct and Indirect Resin Composite Copings for Perio-Overdentures Luted Using Different Adhesive Cementation Modalities. Materials (Basel), 10, 3517. https://doi.org/10.3390/ma13163517

[56] Leguillon, D., Martin, E. and Lafarie-Frenot, M. (2015) Flexural vs. Tensile Strength in Brittle Materials. Comptes Rendus Mecanique, 343, 275-281.

https://doi.org/10.1016/j.crme.2015.02.003

[57] Klein, C.A. (2009) Characteristic Strength, Weibull Modulus, and Failure Probability of Fused Silica Glass. Optical Engineering, 48, Article ID: 113401. https://doi.org/10.1117/1.3265716

[58] Afferrante, L., Ciavarell, M. and Valenza, E. (2006) Is Weibull's Modulus Really a Material Constant? Example Case with Interacting Collinear Cracks. International Journal of Solids and Structures, 43, 5147-5157. https://doi.org/10.1016/j.ijsolstr.2005.08.002

[59] Ashby, M.F. and Jones, D.R.H. (2006) Engineering Materials 2: An Introduction to Microstructure, Processing and Design. 3rd Edition, Pergamon Press, Oxford.

[60] Miura, D., Ishida, Y., Miyasaka, T., Aoki, H. and Shinya, A. (2020) Reliability of Different Bending Test Methods for Dental Press Ceramics. Materials (Basel), 13, 5162. https://doi.org/10.3390/ma13225162

[61] Weibull, W. (1951) A Statistical Distribution Function of Wide Application. Journal of Applied Mechanics, 9, 293-297. https://doi.org/10.1115/1.4010337

[62] Guazzato, M., Albakry, M., Ringer, S.P. and Swain, M.V. (2004) Strength, Fracture Toughness and Microstructure of a Selection of All-Ceramic Materials. Part I. Pressable and Alumina Glass-Infiltrated Ceramics. Dental Materials, 20, 441-448. https://doi.org/10.1016/j.dental.2003.05.003

[63] Abdulhameed, N., Angus, B., Wanamaker, J. and Mecholsky, J.J. (2020) Quantitative Fractography as a Novel Approach to Measure Fracture Toughness of Direct Resin Composites. Journal of the Mechanical Behavior of Biomedical Materials, 109, Article ID: 103857. https://doi.org/10.1016/j.jmbbm.2020.103857

[64] Belli, R., Lohbauer, U., Goetz-Neunhoeffer, F. and Hurle, K. (2019) Crack-Healing during Two-Stage Crystallization of Biomedical Lithium (di) Silicate Glass-Ceramics. 
Dental Materials, 35, 1130-1145. https://doi.org/10.1016/j.dental.2019.05.013

[65] Oh, W.S., Park, J.M. and Anusavice, K.J. (2003) Fracture Toughness (KIC) of a Hot-Pressed Core Ceramic Based on Fractographic Analysis of Fractured Ceramic FPDs. International Journal of Prosthodontics, 16, 135-140.

[66] Bonilla, E.D., Yashar, M. and Caputo, A.A. (2003) Fracture Toughness of Nine Flowable Resin Composites. Journal of Prosthetic Dentistry, 89, 261-267. https://doi.org/10.1067/mpr.2003.33

[67] Albakry, M., Guazzato, M. and Swain, M.V. (2004) Influence of Hot Pressing on the Microstructure and Fracture Toughness of Two Pressable Dental Glass-Ceramics. Journal of Biomedical Materials Research Part B: Applied Biomaterials, 15, 99-107. https://doi.org/10.1002/jbm.b.30066

[68] Urapeopn, S. and Wiriyapak, D. (2017) Effect of Resin Infusion on Fracture Toughness of Dental Veneering Ceramic. Mahidol Dental Journal, 37, 1-6.

[69] Silva, L.H.D., Lima, E., Miranda, R.B.P., Favero, S.S., Lohbauer, U. and Cesar, P.F. (2107) Dental Ceramics: A Review of New Materials and Processing Methods. Brazilian Oral Research, 31, Ariticle No. e58. https://doi.org/10.1590/1807-3107bor-2017.vol31.0058

[70] Evans, A.G. (1990) Perspective on the Development of High-Toughness Ceramics. Journal of the American Ceramic Society, 73, 187-206. https://doi.org/10.1111/j.1151-2916.1990.tb06493.x

[71] Swain, M.V. (1989) Toughening Mechanisms for Ceramics. Materials Forum, 13, 237-253. https://doi.org/10.1016/B978-0-08-034341-9.50261-8

[72] Seghi, R.R. and Sorensen, J.A. (1995) Relative Flexural Strength of Six New Ceramic Materials. International Journal of Prosthodontics, 8, 239-246.

[73] Borba, M., de Araújo, M.D., Fukushima, K.A., Yoshimura, H.N., Cesar, P.F., Griggs, J.A. and Della Bona, A. (2011) Effect of the Microstructure on the Lifetime of Dental Ceramics. Dental Materials, 27, 710-721. https://doi.org/10.1016/j.dental.2011.04.003

[74] Guazzato, M., Albakry, M., Ringer, S.P. and Swain, M.V. (2004) Strength, Fracture Toughness and Microstructure of a Selection of All-Ceramic Materials. Part II. Zirconia-Based Dental Ceramics. Dental Materials, 20, 449-456. https://doi.org/10.1016/j.dental.2003.05.002

[75] Stawarczyk, B., Keul, C., Eichberger, M., Figge, D., Edelhoff, D. and Lümkemann, N. (2017) Three Generations of Zirconia: From Veneered to Monolithic. Part I. Quintessence International, 48, 369-380.

[76] Yilmaz, H., Aydin, C. and Gul, B.E. (2007) Flexural Strength and Fracture Toughness of Dental Core Ceramics. Journal of Prosthetic Dentistry, 98, 120-128. https://doi.org/10.1016/S0022-3913(07)60045-6

[77] Al Hamad, K.Q., Obaidat, I.I. and Baba, N.Z. (2020) The Effect of Ceramic Type and Background Color on Shade Reproducibility of All-Ceramic Restorations. Journal of Prosthodontics, 29, 511-517. https://doi.org/10.1111/jopr.13005

[78] Shenoy, A. and Shenoy, N. (2010) Dental Ceramics: An Update. Journal of Conservative Dentistry, 13, 195-203. https://doi.org/10.4103/0972-0707.73379

[79] Sedda, M., Vichi, A., Del Siena, F., Louca, C. and Ferrari, M. (2014) Flexural Resistance of Cerec CAD/CAM System Ceramic Blocks. Part 2: Outsourcing Materials. American Journal of Dentistry, 27, 17-22.

[80] Miyazaki, T., Nakamura, T., Matsumura, H., Ban, S. and Kobayashi, T. (2013) Current Status of Zirconia Restoration. Journal of Prosthodontic Research, 57, 236-261. 
https://doi.org/10.1016/j.jpor.2013.09.001

[81] Bajraktarova-Valjakova, E., Korunoska-Stevkovska, V., Kapusevska, B., Gigovski, N., Bajraktarova-Misevska, C. and Grozdanov, A. (2018) Contemporary Dental Ceramic Materials, a Review: Chemical Composition, Physical and Mechanical Properties, Indications for Use. Open Access Macedonian Journal of Medical Sciences, 24, 1742-1755. https://doi.org/10.3889/oamjms.2018.378

[82] Pereira, G.K.R., Guilardi, L.F., Dapieve, K.S., Kleverlaan, C.J., Rippe, M.P. and Valandro, L.F. (2018) Mechanical Reliability, Fatigue Strength and Survival Analysis of New Polycrystalline Translucent Zirconia Ceramics for Monolithic Restorations. Journal of Mechanical Behavior of Biomedical Materials, 85, 57-65. https://doi.org/10.1016/j.jmbbm.2018.05.029

[83] Zhang, Y.L. and Zhang, S.Z. (1999) Mechanical Properties and Microstructure of Alumina-Glass Composites. Journal of American Ceramic Society, 82, 1592-1596. https://doi.org/10.1111/j.1151-2916.1999.tb01964.x

[84] Apholt, W., Bindl, A., Lüthy, H. and Mörmann, W.H. (2001) Flexural Strength of Cerec 2 Machined and Jointed In-Ceram Alumina and In-Ceram Zirconia Bars. Dental Materials, 17, 260-267. https://doi.org/10.1016/S0109-5641(00)00080-4

[85] Pradíes, G., Godoy-Ruiz, L., Özcan, M., Moreno-Hay, I. and Martínez-Rus, F. (2019) Analysis of Surface Roughness, Fracture Toughness, and Weibull Characteristics of Different Framework-Veneer Dental Ceramic Assemblies after Grinding, Polishing, and Glazing. Journal of Prosthodontics, 28, e216-e221. https://doi.org/10.1111/jopr.12653

[86] Miyazaki, N. and Hoshide, T. (2018) Influence of Porosity and Pore Distributions on Strength Properties of Porous Alumin. Journal of Materials Engineering and Performance, 27, 4345-4354. https://doi.org/10.1007/s11665-018-3500-x 